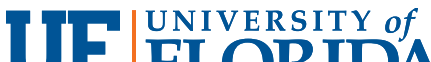 FLORIDA
}

IFAS Extension

\section{Florida Foliage House Plant Care: Adenium obesum ${ }^{1}$}

\author{
R. J. Henny and J. Chen ${ }^{2}$
}

\section{Introduction}

Adenium obesum and its many hybrids are often seen in retail garden centers (Figure 1). They have vibrant floral displays in shades of red, white, pink, and yellow. Flowers average $2-3$ inches in diameter and may be single, double, or even triple. The plants must be stationed in high light, 6 hours or more per day, to maintain flowering during the summer. Adenium obesum makes a dramatic specimen for a deck or patio but should be moved indoors in winter.

Common name: Desert rose

Scientific name: Adenium obesum

Plant family: Apocynaceae (the dogbane family)

\section{Indoor/Home/Office Cultivation Information}

Light requirement: Bright sunlight. Adenium will not flower under low light conditions.

Soil preference: Rich, organic peat or bark-based, bagged potting soil.

Water requirement: Water regularly but do not allow soil to become waterlogged.

Drought tolerant: Yes.

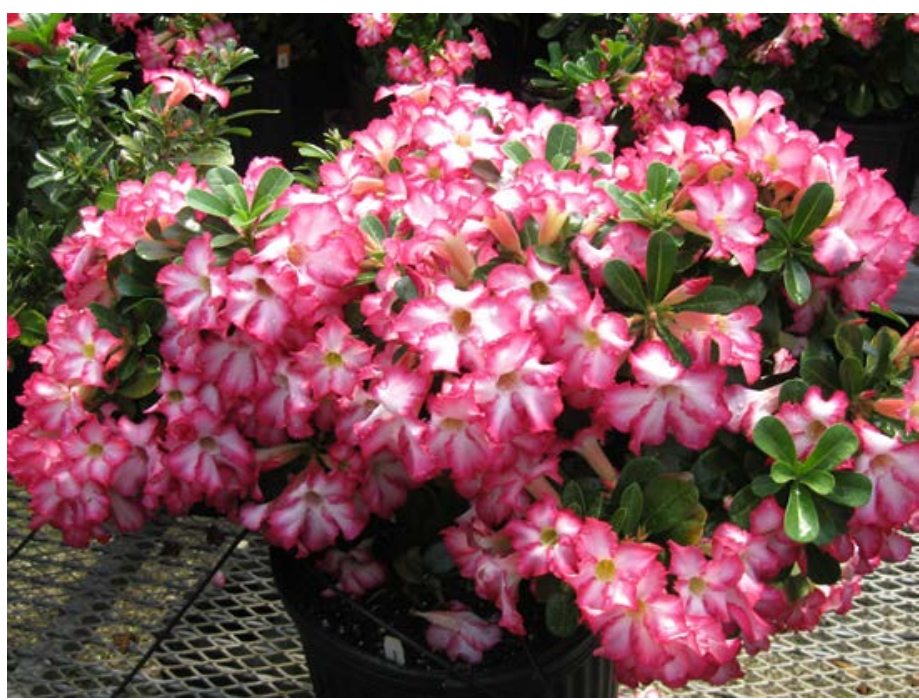

Figure 1. Adenium obesum 'Blooming Fool' in full flower growing in a 10-inch pot.

Credits: R. J. Henny

Fertilizer requirements: Apply a low dose of liquid fertilizer according to manufacturer label recommendations weekly during summer growing season.

Salt tolerant: Some salt tolerance.

Temperature preference: Hot, tropical $75^{\circ} \mathrm{F}-95^{\circ} \mathrm{F}$.

Chill tolerant $\left(55^{\circ} \mathrm{F}-35^{\circ} \mathrm{F}\right)$ : Yes, but leaf yellowing and leaf drop may occur.

Freeze tolerant (below $32^{\circ} \mathrm{F}$ ): No. During cold winter months, withhold water from Adenium and let the plant rest for 3-4 months. All leaves and flowers will drop, but

1. This document is ENH1213, one of a series of the Environmental Horticulture Department, Florida Cooperative Extension Service, Institute of Food and Agricultural Sciences, University of Florida. Original publication date May 2013. Visit the EDIS website at http://edis.ifas.ufl.edu.

2. R. J.Henny and J. Chen, professors, Department of Environmental Horticulture, University of Florida Institute of Food and Agricultural Sciences, Mid-Florida Research and Education Center, Apopka, FL 32703. 
that is part of their natural cycle. DO NOT let them freeze. When temperatures warm again in spring, water and fertilize Adenium. Flowers and foliage will reappear.

Pests: Mealybugs - Take samples to your local Extension agent to confirm identification and receive treatment instructions.

\section{Outdoor Cultivation Information}

Outdoor year-round planting: Okay for USDA Hardiness Zone 10B-12.

Soil preference: Well drained.

Light requirement: Bright sunlight for maximum flowering.

Water requirement: Irrigate regularly but provide drainage.

Drought tolerant: Yes.

Fertilizer requirements: Apply a well-balanced, slow-release pelletized fertilizer according to manufacturer recommendations during the summer.

Salt tolerant: Some salt tolerance.

Temperature preference: Hot, tropical $75^{\circ} \mathrm{F}-95^{\circ} \mathrm{F}$.

Chill tolerant $\left(55^{\circ} \mathrm{F}-35^{\circ} \mathrm{F}\right)$ : Yes, but leaf yellowing and leaf drop may occur.

Freeze tolerant (below $32^{\circ} \mathrm{F}$ ): No. See note about overwintering above.

Pests: Mites, Aphids - Take a sample to your local Extension agent to confirm identification and receive treatment instructions.

Origin: Sub-Saharan regions in Africa.

Notes: Adenium obesum specimens are often "lifted" (root washed) to enhance the caudex (Figure 2). Adenium obesum leaves are dark green and glossy compared to other Adenium species, such as A. swazicum or A. arabicum with their gray-green, velvet-textured leaves.

Availability: Adenium obesum is often seen in garden centers in 8-10-inch pots; larger sizes are available from specialty growers.

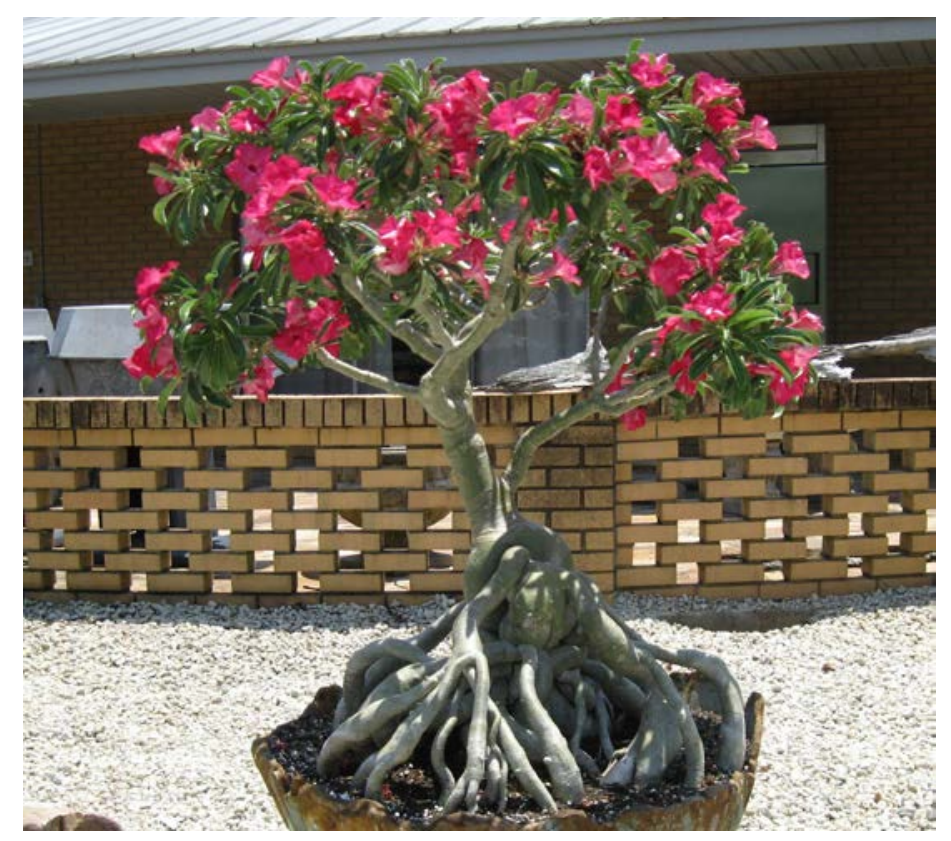

Figure 2. Adenium obesum 'Red' that has been "lifted" (root washed) several times to display the sculptural effect of its roots and caudex. Credits: R. J.Henny

\section{Additional Resources}

Rowley, G. 1999. Adenium and Pachypodium. Cactus File Handbook no. 5. Southampton, UK: Cirio Publishing Services. 